\title{
Female's Infertility Rules of Ultrasound And Colour Duplex in Assessment of Pelvic Causes
}

\author{
Maher B. Ali ${ }^{\text {a }}$, Ahmed F. Yousef ${ }^{\mathrm{b}}$, Hamada M. Khater ${ }^{\mathrm{b}}$
}

\begin{abstract}
${ }^{a}$ Department obstetric and gynecology, faculty of medicine Benha University, Egypt, ${ }^{\text {b }}$ department of Radiodiagnosis and Medical Imaging, faculty of medicine Benha University, Egypt

Correspondence to: Maher B. Ali, Department obstetric and gynecology, faculty of medicine Benha University, Egypt

Email:
\end{abstract}

dr33308@gmail.com

Received: 22 July 2019

Accepted: 15 September 2019

\begin{abstract}
:
Background: The causes of infertility are variable. This study critically evaluates the utility of ultrasound in the diagnosis of the female pelvic pathology. The diagnosis should be more accurate, cost effective, expeditious, reliable and as minimally invasive as possible.

Methods: The data were collected from about 750 infertile women were investigated and chosen sample was 255 cases. All patients underwent two ultrasound examinations in the follicular phase (day 13 of the cycle). Endovaginal ultrasound was done in only 80 of our cases about 60 patients of them were normal and 20 of them were abnormal .13 of them had ovarian causes and 7 had uterine causes. Endovaginal was superior to trans abdominal U/S
\end{abstract}

Results: 119 cases represented U/S abnormalities and the rest were normal according to ultrasound. PCO demonstrated with (73.95\%) of the. other factors represented in only (26.5\%), which was subdivided into; uterine fibroid $(10.92 \%)$, bicornuate and ovarian cystic $(2.52 \%)$, endometriosis, thin endometrium and septate uterus are same percentage (1.68\%), congenital small uterus and ovaries (4.20\%), and PID $(0.84 \%)$,

Conclusion: Ultrasound is one of the non-invasive processes that provides similarly better anatomical and even better physiological data than traditional surgical procedures. The role of ultrasonographic technology, especially trans vaginal, SHG, Doppler and 3D ultrasonography, can improve the female pelvic assessment. Ultrasonographic procedures should be combined as an essential examination in the basic infertility examination.

Key Words:- Colour duplex , infertility, Ultrasound 


\section{Introduction:}

Infertility is one of the major public health problems. It can be defined as loss of the ability to achieve pregnancy after 12 months of unprotected intercourse ${ }^{(4)}$. Another study has considered infertility as a failure to conceive after six months of attempting pregnancy for women with more than 35 years old. ${ }^{(17)}$

The causes of infertility are variable and factors such as physical problems, hormones, lifestyle and environment can contribute to a large extent in unproductivity. Most problems associated with female infertility are related to ovum production with premature ovarian failure as a common cause. This disorder results in the stoppage of the functions of the ovary before the onset of menopause. Polycystic Ovary Syndrome (PCOS) has also been identified as playing a major role in the ovulation. It is a condition where the eggs may not be released regularly or could lead to unhealthy egg production ${ }^{(14)}$.

The diagnosis should be more accurate, cost effective, expeditious, reliable and as minimally invasive as possible to deliver an optimal investigation protocol for infertility. Furthermore, the final diagnosis should provide the clinician with useful prognostic information regarding possible future treatment ${ }^{(8)}$.The aim of this study is to highlight the current role of ultrasound in the evaluation of pelvic causes of infertility in women.

\section{Patients and Methods:}

It is a retrospective study done from April 2018 to June 2019. The data were collected from Benha university hospital and gynaecological hospital in Baghdad - Iraq. During this period about 750 infertile women were investigated. Patients were healthy infertile women from 15-45 years old, presenting with either primary or secondary infertility of more than 12 months. In order to achieve more precise estimates of this population, the sample size calculator was used and it showed that the sample should be 255 cases in order to deliver a $95 \%$ confidence According to this program, this sample size seemed to be an appropriate number to provide evidence of different infertility causes in the given hospitals PROCEDURES approved by ethical committees of Benha university hospital and gynaecological hospital in Baghdad - Iraq

Scan especially in diagnosis of small uterine fibroid and for a more clear texture evulsion ovarian cysts .In addition to that 3 of abnormal cases were suspicious for endometrial lesion underwent sonohysterography with the aid of gynecologist. SHG was definitely more informative regarding the diagnosis of two of 
them as endometrial polyps and one of them as sub mucosal fibroid .Delineating endometrial lesions with saline lead to proper assessment of the nature of these lesions according to their specific ultrasound criteria. Transvaginal examination was only done complementary in 80 cases still since the sample size calculator showed that confident sample should be at least 255 those cases together with those 3 cases underwent $\mathrm{SHG}$ were not officially included in statistical work

All patients underwent two ultrasound examinations in the follicular phase (day 13 of the cycle). All sonographic investigations were accomplished by an expert radiologist with more than 5 years' experience; the scans were performed at different periods with at least one month between the reports to achieve reliability. At real regarding the archived cases usually they were scheduled for regular monthly fellow up. In our statistic we were only restricted to the first two.

Endovaginal ultrasound was done in only 80 our cases about 60 patients of them were normal and 20 of them were abnormal. Thirteen of them had ovarian causes and 7 of them had uterine causes. Endovaginal was superior to transabdominal.

Information was collected using existing data that have been recorded in files and saved in the infertility department of the gynaecological hospital in Iraq. The information depended on the clinical examination and ultrasound reports, which are available in the file for each infertile patient registered at these hospitals. The prospective approach process was used by carrying out a chart review and taking the medical records. The clinical examination was conducted by the gynaecologist, who recorded general information about the patient, such as patient age, type of infertility (primary or secondary) and the hormonal results before sending the patient to an ultrasound examination. Then, a transabdominal ultrasound was requested on the 13th day of cycle if the patient's hormonal results appeared normal in the laboratory test.

\section{Results:}

The following pie chart (fig. 1) shows the two types of infertility, with number 1 at the upper right corner of the chart representing primary infertility and number 2 indicating secondary infertility; primary infertility shows a higher proportion $(58.04 \%)$ and the rest represent secondary infertility.

The graph below purely represents the percentage for each variable as detected by the transabdominal ultrasound in the given population. 


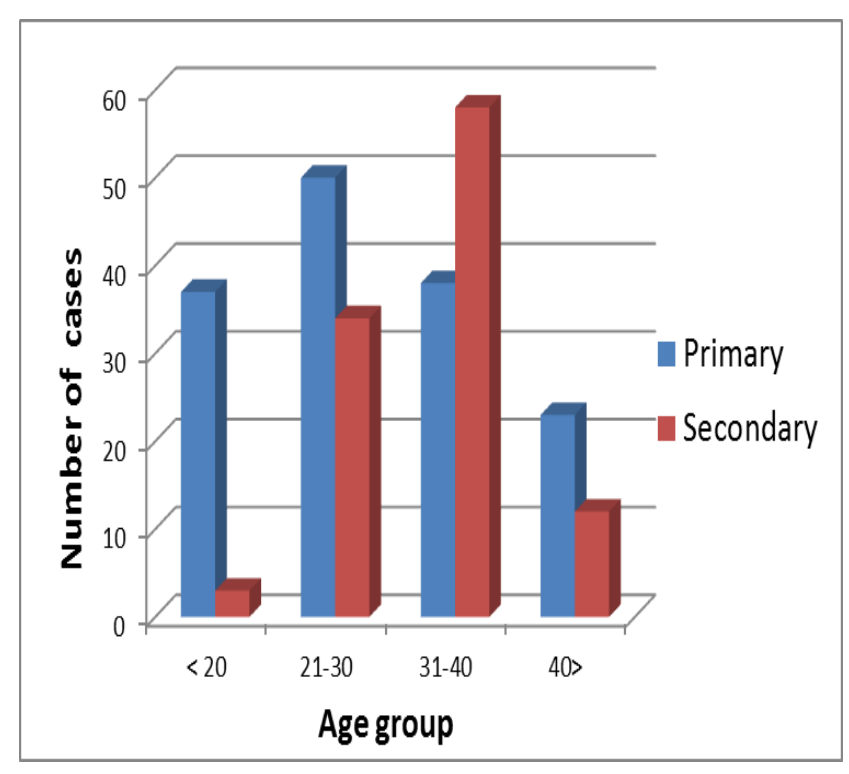

Figure 1. Types of infertility

All the normal patients are excluded. The most striking finding of the data is that, $\mathrm{PCO}$ demonstrated in the majority of the population with $(73.95 \%)$ of the 119 patients who presented with abnormal findings. Other factors represented in only $(26.5 \%)$, which was subdivided into; uterine fibroid with a presentation of 13 women $(10.92 \%)$ of the patients. Bicornuate and ovarian cystic mass have been presented in $(2.52 \%)$, whereas endometriosis, thin endometrium and septate uterus, all were found in the same percentage of $(1.68 \%)$, with only 2 cases for each variable. A congenital small uterus and ovaries were seen in $4.20 \%$ of the abnormal population. The minority of the patients had PID which was identified in one patient with a percentage of $(0.84 \%)$ (fig. 2$)$

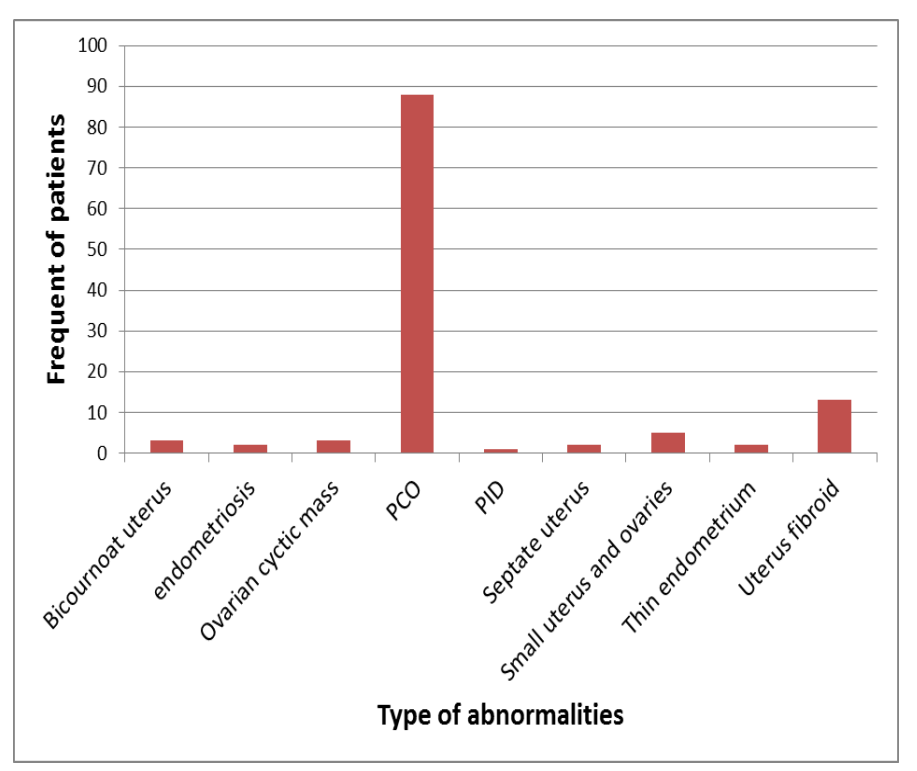

Figure 2. Abnormalities detected in the first ultrasound.

From the studied population, 88 participants had PCO as the most common finding, representing more than one third of the total sample. A remarkable result was that the correlation between PCO and age showed a normal distribution as can be seen in figure (3) below. A similar pattern is observed in figure showing a correlation between the incidence of infertility and age with a similar mean of approximately 30 years old. PCO is mostly noted in patients between 20-40 years old, which is the most common age of women registered with infertility in this study.

The second significant finding was the uterine fibroid represented in 13 women of different age groups with the incidence slightly increasing in relation to age.

The mean age found was 36.38 years, with the majority of cases identified in advancing age of over 40 years women as shown from 
the data in figure (4) below

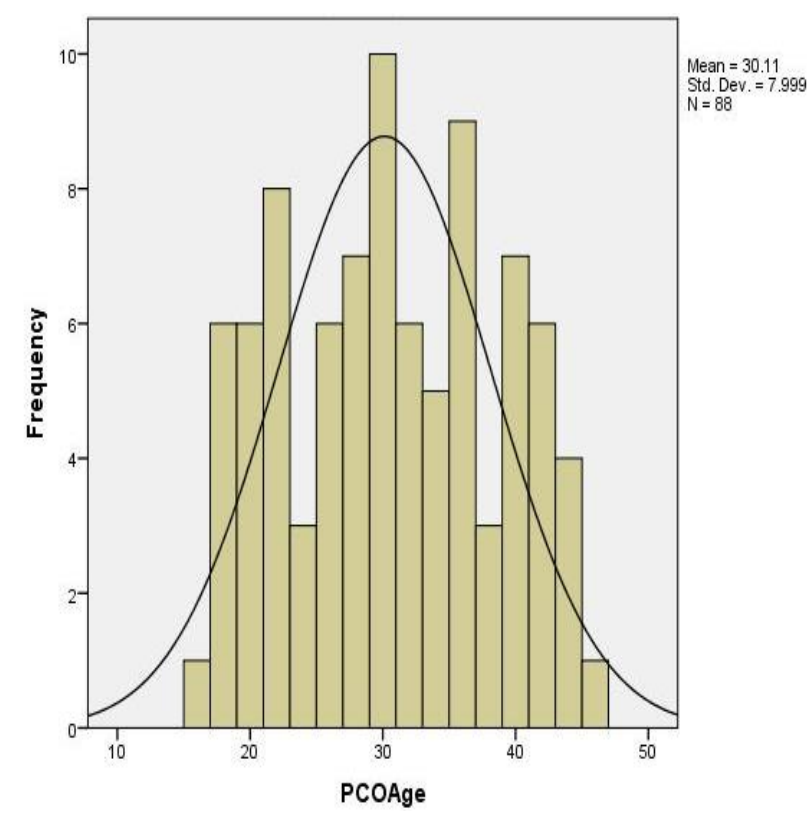

Figure 3: Correlation between the incidences of PCO with patient's age.

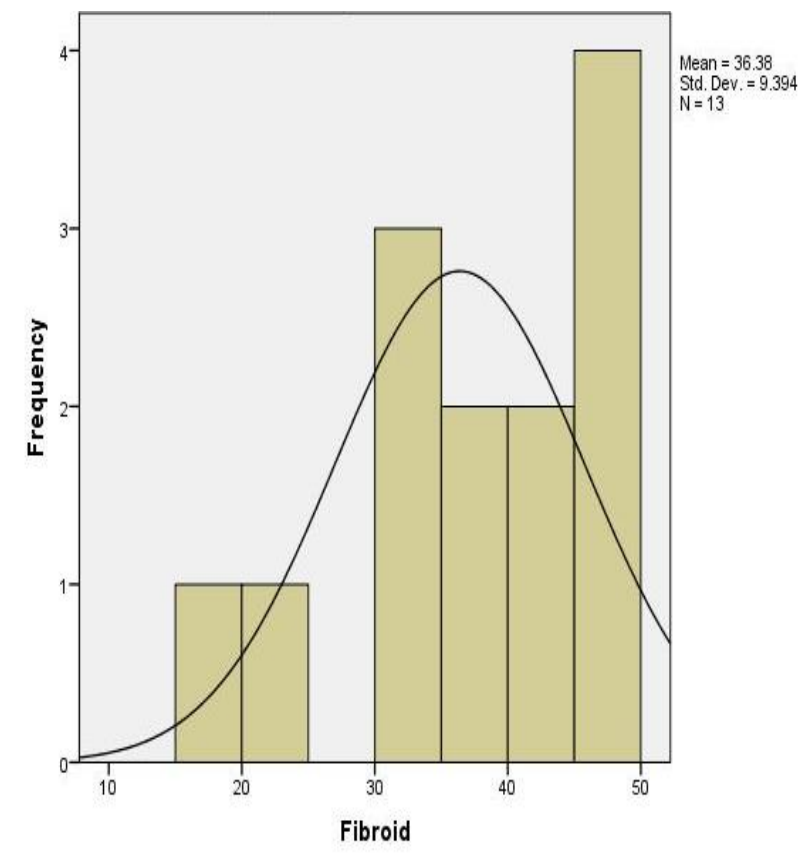

Figure 4: Correlation between the incidences of uterine fibroid and women's age.

\section{Discussion:}

Our study was unfortunately a prospective most of our cases (those taken from archive) were $2 \mathrm{D}$ only 80 cases had a complementary done trans vaginaly examination and only 3 cases had sonohysterography. The results of this study indicate that transabdominal ultrasound has shown an ability to identify some of the uterine, ovarian and adenexal abnormalities, such as uterine fibroid bicornuate uterus, PCO, and endometriosis. Consequently, this result cannot be clearly used for a final assessment since some of the subtle abnormalities cannot be detected by transabdominal 2D ultrasound ${ }^{(10)}$.

Despite the few types of congenital abnormalities identified by the current procedure, the results can be compared to the findings of previous work; for example, ${ }^{(16)}$ reported that the incident can be $3-4 \%$ in the normal population, whereas stated that the incidence varied from $0.06 \%$ and $38 \%$ and this extensive variation is related to the assessment of different patient populations and the use of different diagnostic procedures. Similarly, ${ }^{(2)}$ identified that there is a wide spectrum of uterine abnormalities, whether congenital or acquired, which have a correlation with the presence of infertility.

Ovarian factors were to be the major causal finding of this research. It was presented in $35.69 \%$ of the infertile women, which can be 
compared with previous studies by, ${ }^{(6)}$ who demonstrated that ovarian disorders account for $40 \%$ of infertility conditions. Generally, what is unexpected is that most of the cases presented with PCO (34.5\%) of the selected women. This is predominantly higher than many of the previous results. For example, a review by ${ }^{(13)}$ has shown that PCO is a significant contribution to female sterility due to ovulatory dysfunction and it is estimated to affect 6-8\% of reproductive-aged women.

The prevalence of PCO was $2.2 \%$ to $26 \%$ in a study by ${ }^{(22)}$. However, all these articles measured the incidence in the normal population. In contrast, studies estimating the incidence in the infertile population found that the percentage is much higher which seems to be in agreement with the result of this study even though they used different diagnostic procedure: for example, identified that the rates of PCO in infertile women examined in infertility centers in Britain and United States were 20-25\%, whereas a study by ${ }^{(15)}$ reported the incidence of PCO in women attending the infertility center in the north of Iraq to be $33 \%$ and they showed that the prevalence could reach $40 \%$ in women with infertility.

The second common finding of the current investigation was intrauterine fibroid, presented in 13 patients, 10 of them had intramural fibroid and the remaining presented with submucosal fibroid.
Contrarily, studies by ${ }^{(2)},{ }^{(5)}$ and ${ }^{(18)}$ evidenced that intrauterine fibroma or uterine fibroid was not a major cause of infertility.

In the undertaken study, all patients who had intrauterine fibroid presented with primary infertility giving an impression that this condition should be given more attention in the investigation of infertility causes. It can be clearly seen that the incidence of uterine fibroid tumors increased gradually as women grow older. In accordance with the present results, the review by ${ }^{(9)}$ used ultrasound to identify the prevalence of the uterine fibroid in the normal population and they demonstrated that it varies from $4 \%$ in women from 20 to 30 years of age, to $11-18 \%$ in women from 30 to 40 years and 33 percent in women from 40 to 60 years of age. The incidence could depend on the population studied and the diagnostic method used. In the current study, uterine fibroid presented in 5\% of 255 infertile women or $(10.92 \%)$ from the 119 patients who have ultrasound findings after excluding the normal patients. Numerous studies have attempted to explain the role of uterine fibroid in infertility. However, the correlation is still not clear. Current evidence proposes that submucosal and intramural fibroid tumors, which interfere with the uterine cavity, can cause damage to fertilization ${ }^{(20)}$. The influence of intramural and subserosal fibroid tumors, which have no direct effect on the intrauterine cavity, is still 
uncertain. In spite of the lack of clear evidence of their role in fertility problems, patients with, fibroid tumors larger than $5 \mathrm{~cm}$, multiple fibroid tumors, submucosal uterine fibroid and intramural fibroid tumors which distort the uterine cavity are often regarded and treated in patients with unexplained infertility. ${ }^{(1)}$

Another ultrasound finding was the endometriosis. A strong relationship between endometriosis and infertility had been reported in the previous studies. The data suggested that, endometriosis may have an unfavorable effect on productivity. A higher incidence has been recorded in infertile women and it is estimated that 30 to $71 \%$ of infertile women have endometriosis and the prevalence in asymptomatic women varies from 2 to $20 \%$, and it ranges from 15 to $45 \%$ in women with pelvic pain (11). (3) Some studies showed that the overall incidence was $5 \%$ to $10 \%$. (3) However, this prevalence depends on the diagnostic criteria. The precise occurrence of the disease is difficult to establish because the definitive diagnosis required further investigation such as laparoscopy or surgery. In this study the incidence was only $2.52 \%$. This research also did not find a significant incidence of the other possible causes of infertility. Very few other abnormal cases were noticed, such as thin endometrium, PID, and ovarian mass, whereas PID may present in more than half of the patients who have tubo-peritoneal infertility factors as demonstrated by ${ }^{(19)}$. A possible explanation for this low result in this study may be due to the relatively low sample size and to the fact that we were mainly restricted to $2 \mathrm{D}$ study in $69 \%$ in of our cases which is would definitely missed most of these cases.

Generally, transabdominal and transvaginal US are readily available diagnostic modalities, which are widely accepted and utilized. It may play a useful role in the assessment of the presence of abnormalities in the entire pelvis ${ }^{(10)}$. The advantage of US is that it allows measurements and quantification of observations to be made. However, in some case it cannot exactly specify the finding, for example, ultrasound can detect the pathological tube only if the tube distended by fluid such as obstruction with inflammation or ectopic pregnancy ${ }^{(7)}$, therefore, further techniques can be used as a supplementary procedure to confirm the finding such as SHG with 3D and Doppler US (21). These techniques can be performed in one scan, which limits the time and cost of the diagnostic procedures.

\section{References:}

1. Bajekal, N, \& LI, T.C. (2000). Fibroids, infertility and pregnancy wastage. Human reproduction update, 6(6), pp. 614-620. [Online]. Available at: http://humupd.oxfordjournals.org/content/6/6/614. short. [Accessed October 27, 2014]. 
2. BRUGO-OLMEDO, S., CHILLIK, C. \& KOPELMAN, S. (2002). Review Definition and causes of infertility. Reproductive BioMedicine, 2 (1), pp.173-185. [Online]. Available at: http://dx.doi.org/10.1016/S1472-6483 (10)621931. [Accessed November 5, 2014].

3. CARBOGNIN, G., (2004). Pelvic endometriosis: US and MRI features. Abdominal imaging, 29 (5), pp.609-18. [Online]. Available at: http://www.ncbi.nlm.nih.gov/pubmed/15162229.

[Accessed November 5, 2014].

4. Carnegie, D. (2013). Evaluation of Infertile Female Patients. Textbook of in Vitro Fertilization, 335. [Online]. Available at: http://books.google.co.uk. [Accessed December 2015.

5. CHOUSSEIN, S. \& VLAHOS, N.F. (2012). Female Fertility Assessment. Current Obstetrics and Gynecology Reports, 1 (4), pp.174-181. [Online]. Available at: http://link.springer.com/10.1007/s13669-0120022-7. [Accessed September 23. 2013)

6. Cocksedge, K. \& LI, T Saravelos, S.,. (2008). Prevalence and diagnosis of congenital uterine anomalies in women with reproductive failure: a critical appraisal. Human Reproduction Update, 14 (5), pp.415-429.[Online]. Available at: http:// humupd. oxfordjournals. org/content/ 14/5 1415.short. [Accessed September 22, 2014].

7. Derchi and L.E. (2001). Ultrasound in gynaecology. European radiology, 11 (11), pp. 2137-55. [Online] Available at: http:// www. ncbi. nlm. nih. gov/ pubmed/ 11702153. [Accessed September 23, 2014].

8. Ekerhovd, L E., FRIED, G. GRANBERG, S. (2004). An ultrasound-based approach to the assessment of infertility, including the evaluation of tubal patency. Best Practice \& Research, 18 (1), pp. 13-28. [Online]. Available at: http://www.sciencedirect.com / science/ article/ pii/ S1521693403001366. [Accessed September 22, 2014].

9. EVANS, P. \& BRUNSELL, S. (2007). Uterine fibroid tumors: diagnosis and treatment. Am Fam Physician. 75 (10), [Online]. Available at: http://www.monografias.com/ .pdf. [Accessed December 19, 2014].

10. Gill, K.A. (2014). Ultrasound in Obstetrics and Gynecology: a practitioner's guide. Copyright (C) 2014 by Davies Publishing, Inc. [Online]. Available at: http://www.daviespublishing.com .pdf [Accessed January 14, 2015].

11. HALIS, G. \& ARICI, A. (2004). Endometriosis and inflammation in infertility. Annals of the New York Academy of Sciences, 1034 (1), pp. 30015.[Online]. Available at: http://www.ncbi.nlm. [Accessed November 8, 2014].

12. Haq, F., Aftab, O. \& Rizvi, J.(2007). Clinical, biochemical and ultrasonographic features of infertile women with polycystic ovarian syndrome. J Coll Physicians Surg Pak, 17 (2), pp. 76-80. [Online]. Available at: http://jcpsp.pk/archive/2007/Feb2007/article4.pdf. [Accessed December 19, 2014].

13. Harris G. M. \& MCLAREN, J. (2013). Role of female pelvic anatomy in infertility. Clinical Anatomy, 96 (October 2012), pp. 89-96. [Online]. Available at: http://onlinelibrary.wiley.com/ . [Accessed September 22, 2014].

14. Hornstein. (2016) Optimizing natural fertility in couples planning pregnancy. http:// WwW. uptodate. com/ home. Accessed May 10, 2016.

15. Hussein, B. \& Alalaf, S. (2013). Characteristics of polycystic ovarian syndrome in a sample of infertile Kurdish women attending IVF infertility center in maternity teaching hospital of Erbil City. Open Journal of Obstetrics and Gynecology, 2013 (September), pp.577-585. [Online]. Available at: 
http:// file. scirp. Org /Html /13-1430480_37028. htm. [Accessed December 19, 2014].

16. Lankford, J.C., Mancuso, P. \& Appel, R. (2013). Congenital Reproductive Abnormalities. Journal of midwifery \& women's health, pp.546-551. [Online]. Available at: http:// www. ncbi. nlm. nih. gov/ pubmed/ [Accessed September 23, 2014].

17. Mclaren, JF. (2012). Infertility evaluation. Obstetrics and gynecology clinics of North America, 39 (4), pp. 453-463. [Online]. [Accessed December 22, 2014].

18. Niknejadi, M. (2012). Diagnostic accuracy of transvaginal sonography in the detection of uterine abnormalities in infertile women. Iranian journal of radiology: , 9(3), pp.139-44. [Online]. Available at: http:// www. pubmedcentral. [Accessed December 19, 2014].

19. Patrelli, franchi 1, gizzo S, .(2013). Can the impact of pelvic inflammatory disease on fertility be prevented? Epidemiology, clinical features and surgical treatment: evolution over 8 years. The
Journal of reproductive medicine, 58 (9-10), 425-

433. [Online]. Available at http://europepmc.org/abstract/MED/24050032. [Accessed January 13, 2015].

20. Rackow, \& Arici, A. (2005). Fibroids and in-vitro fertilization: which comes First? Current Opinion in Obstetrics and Gynecology, 17 (3), 225-231.

21. Saravelos, S. Cocksedge, K. \& LI, T,. (2008). Prevalence and diagnosis of congenital uterine anomalies in women with reproductive failure: a critical appraisal. Human Reproduction Update, 14 (5), pp.415-429.[Online]. Available at: http:// humupd. oxfordjournals. org/content/ 14/5 1415.short. [Accessed September 22, 2014].

22. Tehrani, and F.R., (2011). The prevalence of polycystic ovary syndrome in a community sample of Iranian population: Iranian PCOS prevalence study. Reproductive biology and endocrinology : , 9 (1), p.39.[Online] Available at:http://www.pubmedcentral.nih.gov/ . [Accessed December 19, 2014].

To cite this article: Maher B. Ali , Ahmed F. Yousef, Hamada M. Khater, Femal's Infertility rules of ultrasound \& colour duplex in assessment of pelvic causes, BMFJ, 2019;36(3):89-97 DOI: 10.21608/bmfj.2020.15111.1022 